\title{
Role of the lung resistance-related protein (LRP) in the drug sensitivity of cultured tumor cells
}

\author{
S. Meschini ${ }^{\mathrm{a}}$, M. Marra ${ }^{\mathrm{a}}$, A. Calcabrini ${ }^{\mathrm{a}}$, E. Monti ${ }^{\mathrm{b}}$, M. Gariboldi ${ }^{\mathrm{b}}$, \\ E. Dolfinic ${ }^{\mathrm{c}}$ G. Arancia ${ }^{\mathrm{a}, *}$ \\ ${ }^{a}$ Laboratory of Ultrastructures, Istituto Superiore di Sanità, Viale Regina Elena 299, 00161 Rome, Italy \\ ${ }^{\mathrm{b}}$ Department of Structural and Functional Biology, University of Insubria, Varese, Italy \\ ${ }^{\mathrm{c}}$ Department of Biology and Genetics for Health Sciences, University of Milan, Milan, Italy
}

\begin{abstract}
Drug resistance, one of the major obstacle in the successful anticancer therapy, can be observed at the outset of therapy (intrinsic resistance) or after exposure to the antitumor agent (acquired resistance). To gain a better insight into the mechanisms of intrinsic resistance we have analyzed two human cell types derived from untreated tumors: MCF-7 breast cancer and A549 non small cell lung cancer (NSCLC). We have examined: the cytotoxic effect induced by doxorubicin (DOX); the time course of drug accumulation by flow cytometry and intracellular drug distribution by confocal microscopy; the expression and distribution of proteins related to anthracycline resistance, such as P-gp (P-glycoprotein), MRP1 (multidrug resistance-associated protein) and LRP (lung resistance-related protein). The cytotoxicity assays showed that A549 cells were less sensitive than MCF-7 cells to the DOX treatment in agreement with the different DOX uptake. Moreover, while in A549 cells DOX was mostly located in well defined intracytoplasmic vesicles, in MCF-7 cells it was mainly revealed inside the nuclei. The analysis of P-gp and MRP expression did not show significant differences between the two cell lines while a high expression of LRP was detected at the nuclear envelope and cytoplasmic levels in A549 cells. These findings suggest that the lower sensitivity to DOX treatment showed by lung carcinoma cells could be ascribed to drug sequestration by LRP inside the cytoplasmic compartments. (C) 2002 Elsevier Science Ltd. All rights reserved.
\end{abstract}

Keywords: Transport proteins; LRP; Drug sensitivity; Cultured tumor cells; Flow cytometry; Confocal microscopy

\section{Introduction}

Successful chemotherapeutic treatment of tumors is often seriously hampered by their poor response to anticancer drugs. In fact, tumor cells can be insensitive to drug treatment at the outset of therapy, thus exhibiting an intrinsic resistant phenotype (Childs and Ling, 1994).

The mechanisms responsible for intrinsic drug resistance are still poorly understood. It is well known that tumor cells exposed to antineoplastic agents may develop, both in vivo and in vitro, a multidrug resistant (MDR) phenotype, which is generally associated with

Abbreviations: BSA, bovine serum albumin; DOX, doxorubicin; FCS, fetal calf serum; HBSS, Hanks' balanced salt solution; LRP, lung resistance-related protein; MDR, multidrug resistant; MFC, mean fluorescence channel; MRP, multidrug resistance-associated protein; MVP, major vault protein; NSCLC, non-small-cell lung cancer; PBS, phosphate buffered saline; P-gp, P-glycoprotein; SCLCs, small-cell lung cancers; SEM, scanning electron microscopy.

* Corresponding author. Tel.: +39-06-4990-3405; fax: +39-064938-7140. altered expression of drug transporter proteins, such as P-glycoprotein (P-gp) (Gottesman and Pastan, 1993; Shapiro and Ling, 1995) and the family of multidrug resistance-associated proteins (MRPs) (Cole et al., 1992; Berger et al., 1997). These proteins act as ATP-dependent molecular pumps, which extrude a number of antitumor drugs from the cell, thus decreasing their concentrations at intracellular targets. It is generally believed that an intrinsic MDR phenotype is caused by multiple mechanisms; recent evidence suggests that changes in transport proteins may also contribute to this more elusive form of drug resistance (Berger et al., 2000; Meschini et al., 2000). Recently, overexpression of a $110 \mathrm{kDa}$ vesicular protein, termed lung resistancerelated protein (LRP), has been demonstrated in a number of tumor cell lines intrinsically resistant to chemotherapeutic drugs (Laurencot et al., 1997). LRP has been found to be identical with the human major vault protein (MVP), which is the major component of vaults (Scheffer et al., 1995; Izquierdo et al., 1996). Vaults are multisubunit complexes of ribonucleoprotein 
particles exhibiting an octagonal barrel-shaped structure, with protruding caps and an invaginated waist. These structures are highly conserved among eukaryotes, suggesting that they are essential for cell function (Kedersha et al., 1990); however, their physiological role in normal tissues and in intrinsic or acquired drug resistance is yet to be defined. Vaults are mainly located within the cytoplasm, where they exhibit a punctate distribution, while a minor fraction concurs to the formation of nuclear pore complexes. Therefore, based on their subcellular localization, vaults have been implicated in vesicular and nucleocytoplasmic drug transport (Scheffer et al., 1995). In fact, the entrapment of drugs into vesicular compartments and decreased nuclear/cytoplasmic ratios have been observed in some MDR cell lines overexpressing LRP (Dietel et al., 1990; Schuurhuis et al., 1991).

While one or more drug transport proteins may contribute to the intrinsic MDR phenotype, a more general mechanism for drug resistance has recently emerged and has gained increasing popularity with tumor cell biologists, namely the inability of cells to undergo apoptosis, which is now generally acknowledged as leading to cell death upon exposure to anticancer agents. Intrinsic or acquired defects in the apoptotic machinery could therefore profoundly alter the therapeutic outcome and have become an area of active research.

To investigate the mechanisms responsible for intrinsic drug resistance, we have analyzed two different human cell lines, MCF-7 (breast carcinoma) and A549 (non small cell lung carcinoma, NSCLC). Both cell lines were derived from untreated tumors and their response to chemotherapeutic agents is a fair reproduction of the clinical behaviour of the tumor types from which they originated. Breast adenocarcinomas, which represent the most common form of cancer in women, usually respond to pharmacological and endocrine treatments at the outset of therapy, even though they frequently progress from hormone-dependent to hormone-independent growth, and very easily acquire MDR and metastatic properties (Clarke et al., 1990; Leonessa et al., 1992). Lung cancers are classified in 2 main histological groups, small cell lung cancers (SCLCs) and non small cell lung cancers (NSCLCs). The latter are especially characterized by a poor prognosis (Cole et al., 1992; Doyle, 1993); NSCLCs are frequently chemoresistant from diagnosis and in vitro NSCLC cells often exhibit an intrinsic multidrug resistant phenotype (Scheper et al., 1993). Only low amounts of the MDR1 gene product have been detected in unselected NSCLC cell lines, suggesting that other mechanisms could be involved in the intrinsically resistant phenotype (Doyle, 1993). Overexpression of LRP, originally observed in a NSCLC cell line selected for resistance against doxorubicin (DOX) and subsequently detected in other cell lines of different histogenetic origin (Scheper et al.,
1993; Scheffer et al., 1995), has been proposed to play a major role in this phenomenon.

In the present study, we have examined: (1) the cytotoxic effect induced by DOX treatment in MCF-7 and A549 cells and the ability of the cells to undergo apoptosis in response to drug treatment; (2) the time course of drug accumulation by flow cytometric analysis and the intracellular distribution of the drug by laser confocal microscopy; and (3) the intracellular levels and distribution of transport proteins related to anthracycline resistance, including P-gp, MRP1 and LRP.

Our data seem to indicate that the lower sensitivity to doxorubicin observed in A549 non small lung cancer cells is mainly due to the high intracellular expression of LRP. Moreover, the association of LRP with intrinsic drug resistance in vitro has been pointed out and the potential value of this protein as marker of clinical drug resistance has been argued.

\section{Materials and methods}

\subsection{Cell cultures}

Two human drug sensitive cell lines, A549 (non small cell lung cancer, NSCLC) and MCF-7 (breast adenocarcinoma) were used. These cells grow as monolayer in RPMI 1640 medium supplemented with $10 \%$ FCS, $1 \%$ L-glutamine and $0.1 \%$ gentamycin at $37{ }^{\circ} \mathrm{C}$ in a $5 \%$ $\mathrm{CO}_{2}$ humidified atmosphere in air.

\subsection{Cytotoxicity studies}

Growth inhibition by DOX was determined by the MTT assay (Alley et al., 1988). Approximately 3000 5000 cells per well were seeded onto 96-well plates and allowed to attach for $24 \mathrm{~h}$ before treatment with a range of drug concentrations for 5 days. A 5-day exposure time was chosen to allow the cells to grow in the presence of the drug for at least two doubling times. Initial cell densities were adjusted accordingly to obtain a 80 $90 \%$ confluent monolayer in control wells at the end of the experiment.

\subsection{Scanning electron microscopy}

For scanning electron microscopy (SEM) studies, cells grown on coverslips were fixed with $2.5 \%$ glutaraldehyde in $0.1 \mathrm{~m}$ cacodylate buffer ( $\mathrm{pH} 7.3$ ) added with $2 \%$ sucrose at room temperature for $20 \mathrm{~min}$. After postfixation with $1 \% \mathrm{OsO}_{4}$ in $0.1 \mathrm{~m}$ cacodylate buffer (pH 7.3) at room temperature for $30 \mathrm{~min}$, cells were dehydrated through graded ethanol concentrations, critical point-dried in $\mathrm{CO}_{2}$ (CPD 030 Baltec device, Balzers, Liechtenstein) and gold coated by sputtering (SCD 040 Balzers device). The samples were then examined 
with a Cambridge Stereoscan 360 scanning electron microscope (Cambridge Instruments, Cambridge, UK).

\subsection{Apoptosis evaluation by Hoechst labelling}

Cell lines were exposed for 24,48 and $72 \mathrm{~h}$ to $2 \mu \mathrm{M}$ DOX, rinsed twice with PBS, fixed with $3 \%$ paraformaldehyde in PBS for 10 min and then stained with 5 $\mu \mathrm{g} / \mathrm{ml}$ Hoechst 33342 (Molecular Probes, Interchim, Asnières, France) to evaluate morphological DNA features. Fluorescence microscopy analysis was performed with a Nikon Microphot-SA fluorescence microscope (Nikon, Tokyo, Japan) with an excitation and emission wavelenghts of $330-385 \mathrm{~nm}$ and $420-460 \mathrm{~nm}$, respectively. Cells were classified as "normal" when the nuclei were intact and exhibited uncondensed chromatin, as "apoptotic" when perinuclear condensed chromatin or apoptotic bodies were revealed. All analyses were performed by morphological examination of at least 100 cells per sample and repeated at least twice.

\subsection{MAb reagents}

For flow cytometric and fluorescence microscopy analyses, intracytoplasmic P-gp was labelled with MAb MRK16 (Kamiya Biomedical Company, Thousand Oaks, CA), a mouse $\mathrm{IgG}_{2 \mathrm{a}}$ immunoglobulin that recognizes a conformational epitope distributed on the 1st and 4st loops of P-gp molecule. The concentration used for these studies was $10 \mu \mathrm{g} / \mathrm{ml}$.

For MRP1 detection, MAb MRPr1 (Kamiya), a rat $\mathrm{IgG}_{2 \mathrm{a}}$ immunoglobulin which reacts with an internal epitope of MRP1 and does not cross-react with the human MDR1 gene product (Flens et al., 1994), was employed. The optimal concentration for this antibody in flow cytometry and immunocytochemistry studies was $1 \mu \mathrm{g} / \mathrm{ml}$.

For LRP detection, MAbs LRP-56 ( $\operatorname{IgG}_{2 \mathrm{~b}}$; Signet Laboratories Inc., Dedham, MA) and LRP-42 (IgG 1 ; Transduction Laboratories, Lexington, KY) directed against different epitopes of LRP (Scheper et al., 1993; Berger et al., 1997) were employed. These MAbs were used at a final working concentration of $0.2 \mu \mathrm{g} / \mathrm{ml}$ and $0.5 \mu \mathrm{g} / \mathrm{ml}$, respectively. The control isotype antibodies used were obtained from Sigma (Sigma Chemical Company, St. Louis, MO).

\subsection{Confocal microscopy}

The analysis of the intracellular distribution of DOX was carried out by confocal laser scanning microscopy by taking advantage of the intrinsic fluorescence of the drug. The observations were performed on living cells, grown on 13-mm glass coverslips, mounted on microscope slides in the presence of the growth medium and analysed under oil immersion objective. In order to avoid cell damage, the image acquisitions were quickly made on several cells present on different coverslips for each sample, acquiring signals coming from one field per coverslip. The samples were incubated with $2 \mu \mathrm{M}$ DOX for $10 \mathrm{~min}, 30 \mathrm{~min}, 1 \mathrm{~h}$ and $4 \mathrm{~h}$ at $37^{\circ} \mathrm{C}$. The cells were also observed without any treatment, under the same instrumental conditions, in order to detect the spontaneous autofluorescence. A very weak and diffuse fluorescence was emitted by untreated cells.

To detect intracellular expression of LRP, cells were fixed with freshly prepared $3.7 \%$ formaldehyde in PBS ( $\mathrm{pH}$ 7.4) for $10 \mathrm{~min}$ at room temperature and subsequently permeabilized with $0.5 \%$ Triton X-100 (Sigma) in PBS for 5 min. After washings in PBS, the samples were labelled either with MAb LRP-56 or MAb LRP-42 and subsequently with a goat anti-mouse IgG fluorescein-conjugate (Sigma). Incubations with primary and secondary antibodies were performed for $30 \mathrm{~min}$ at $4{ }^{\circ} \mathrm{C}$ in PBS containing $1 \%$ bovine serum albumin (BSA, Sigma), $10 \%$ fetal calf serum and $10 \%$ human $\mathrm{AB}$ serum (Sigma).

The observations were carried out with a Sarastro 2000 confocal laser scanning microscope (Molecular Dynamics, Sunnyvale, CA) equipped with a $25-\mathrm{mW}$ argon laser coupled to an epifluorescence Nikon Optiphot microscope with a $60 \times$ oil-immersion objective lens $(\mathrm{NA}=1.4)$. The excitation and emission wavelengths employed were $488 \mathrm{~nm}$ and $510 \mathrm{~nm}$, respectively. The images were acquired in average accumulation mode (two scans in each section), with an image size of $1024 \times 1024$ pixels and pixel size of $0.08 \mu \mathrm{m}$. The optical sectioning was carried out with $0.9 \mu \mathrm{m}$ step size.

\subsection{Flow cytometry}

All flow cytometric analyses were carried out on cell suspensions $\left(10^{6}\right.$ cells $\left./ \mathrm{ml}\right)$ obtained by incubating monolayer cell cultures with EDTA and trypsin.

To detect intracellular expression of P-gp and LRP, cell suspensions were fixed with $2 \%$ paraformaldehyde in PBS for $10 \mathrm{~min}$ at $4{ }^{\circ} \mathrm{C}$. The samples were then permeabilized by adding $0.05 \%$ Triton $\mathrm{X}-100$ for $10 \mathrm{~min}$ at $4{ }^{\circ} \mathrm{C}$. Incubations with the primary (MRK16, LRP-56, LRP-42) and secondary (goat anti-mouse IgG fluorescein-conjugate) antibodies were performed for $30 \mathrm{~min}$ at $4{ }^{\circ} \mathrm{C}$ in PBS containing $1 \%$ BSA, $10 \%$ fetal calf serum and $10 \%$ human $\mathrm{AB}$ serum. For negative controls, cells were labelled with mouse isotypic globulins.

For MRP1 detection with MAb MRPr1, cells were permeabilized in $10 \%(\mathrm{v} / \mathrm{v})$ lysing solution $\mathrm{G}$ (Becton Dickinson, Mountain View, CA) in $\mathrm{dH}_{2} \mathrm{O}$ and incubated for $15 \mathrm{~min}$ in PBS/BSA containing $1 \%$ normal goat serum. Cells were then incubated for $45 \mathrm{~min}$ at $4{ }^{\circ} \mathrm{C}$ with the MRPr1 antibody; after washings with PBS, cells were incubated with a goat anti-rat $\mathrm{IgG}$ fluorescein-conjugate. For negative controls, cells were incubated with rat isotypic globulins. 
Time course studies of drug accumulation were performed on MCF-7 and A549 cells treated with $2 \mu \mathrm{M}$ DOX for 1 and $4 \mathrm{~h}$. At the end of treatments, cells were washed with ice-cold Hank's balanced salt solution (HBSS, Sigma), detached with EDTA and trypsin, resuspended in ice-cold PBS and immediately analyzed for DOX content.

Fluorescence was analyzed with a FACScan flow cytometer (Becton Dickinson) equipped with a $15-\mathrm{mW}$, $488 \mathrm{~nm}$, air-cooled argon ion laser. The fluorescence emissions were collected through a $530 \mathrm{~nm}$ band-pass filter for fluorescein and a $575 \mathrm{~nm}$ band-pass filter for DOX and acquired in log mode. For DOX accumulation studies, drug fluorescence intensity was expressed as the mean fluorescence channel (MFC) calculated from the flow cytometric profiles by the Cell Quest software (Becton Dickinson).

For quantitative evaluation of P-gp, MRP and LRP expression, protein content was expressed in arbitrary units (A.U.) and obtained as the ratio of the MFC of labelled samples on the MFC of negative controls.

\subsection{Immunoprecipitation}

Approximately $10^{7}$ cells were washed 3 times in cold PBS and incubated for $30 \mathrm{~min}$ on ice in lysis buffer [PBS with 1mm EDTA, $1 \mathrm{~mm}$ phenylmethylsulfonyl fluoride (Sigma) and 1\% Nonidet P-40 and protease inhibitor coktail tablet (Boheringer Mannheim, Germany)]. Nuclei and unsolubilized cell membranes were removed by centrifugation at $14,000 \mathrm{rpm}$ for $10 \mathrm{~min}$. Supernatants were aliquoted into $1.5 \mathrm{ml}$ conich tubes supplemented with $1 \%$ non fat milk powder and precleared with $100 \mu \mathrm{l}$ protein $\mathrm{A} / \mathrm{G}$ Plus-Agarose (diluted 1:1 in PBS, Santa Cruz Biotechnology, CA) to reduce nonspecific binding. The samples were spinned at 14,000 $\mathrm{rpm}$ for $15 \mathrm{~min}$ at $4{ }^{\circ} \mathrm{C}$; supernatants were then incubated with $15 \mu$ of undiluted LRP-56 $(1 \mathrm{mg} / \mathrm{ml})$ or with an equivalent amount of an irrelevant mouse $\operatorname{IgG}_{2 b}$ antibody for $2 \mathrm{~h}$ at $4{ }^{\circ} \mathrm{C}$. Immune complexes were precipited by further incubation for $1 \mathrm{~h}$ at $4{ }^{\circ} \mathrm{C}$ with $100 \mu \mathrm{l}$ protein A/G Plus-Agarose (1:1 in PBS). Precipitates were washed twice with lysis buffer supplemented with $0.1 \%$ sodium dodecyl sulphate and four times with PBS, and resuspended in $50 \mu \mathrm{l}$ sample buffer [200 mM TrisHCL (pH 6.8), 1\% 2-mercaptoethanol, 8\% sodium dodecylsulfate, $10 \%$ glycerol and $0.05 \%$ bromophenol blue]. After centrifugation, supernatants were analyzed on $7.5 \%$ SDS-PAGE. Gel was stained with Silver Stain Plus kit (Bio-Rad Laboratories, Richmond, CA) according to the manufacturer's instructions.

\subsection{Statistical analysis}

The values reported in the figures are the means \pm standard deviation (S.D.) from four to six indepen- dent experiments. Statistical analyses were performed using Student's $t$-test. A $P$ value lower than 0.05 was considered significant (asterisk in table and figures).

\section{Results}

\subsection{Morphological characterization by SEM}

Scanning electron microscopy of exponentially growing (about $48 \mathrm{~h}$ from seeding) MCF-7 and A549 cell monolayers evidenced morphological differences between the two cell lines. Breast carcinoma cells (MCF-7) appeared to be heterogeneous in size and shape, and their surface was covered by abundant, densely packed microvilli (Plate 1a); a number of roundish cells poorly adherent to the substratum was detected. Conversely, lung cancer cells (A549) were quite homogeneous in morphology (Plate 1b). Most of A549 cells appeared to be large, flattened, well adherent to the substratum, with short and sparse microvilli projecting from the cell surface.
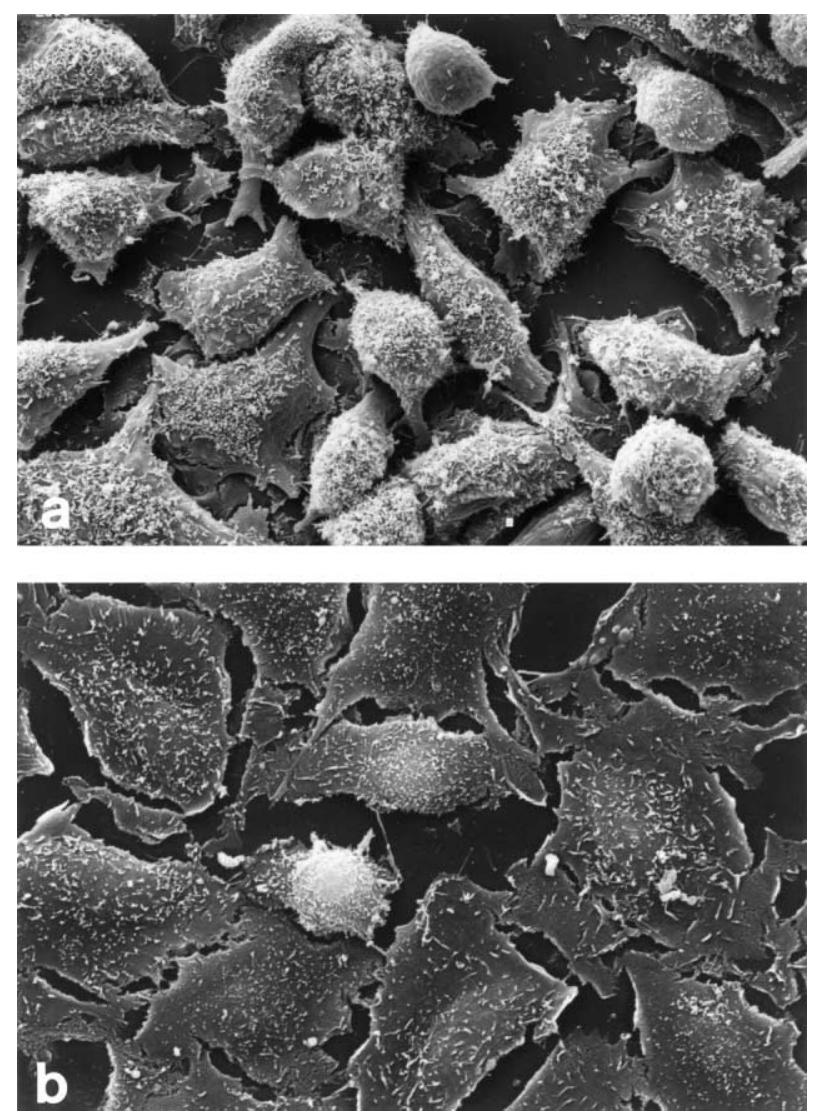

Plate 1. Scanning electron micrographs of (a) MCF-7 and (b) A549 cells. Breast carcinoma cells appeared to be heterogeneous in size and shape while lung cancer cells showed to be large, flattened with short and sparse microvilli $(\times 800)$. 


\subsection{Drug sensitivity}

The cytotoxic effect of doxorubicin on the two cell lines, expressed as the $\mathrm{IC}_{50}$ values, has been determined by the MTT assay. Table 1 shows the mean $\mathrm{IC}_{50}$ values ( \pm S.D.) obtained from four independent experiments. In agreement with the low drug sensitivity of NSCLC cells, A549 cells were about 40 times more resistant to DOX treatment than MCF-7 cells.

\subsection{Detection of apoptotic nuclei}

Fluorescence microscopy observations of control and DOX-treated cells after Hoechst staining were carried out. The quantitative analysis revealed that the percentage of apoptotic cells (condensed chromatin and/or fragmented nuclei) after $72 \mathrm{~h}$ of treatment with $2 \mu \mathrm{M}$ DOX was significantly higher in $\mathrm{MCF}-7$ cells (about $35 \%$ ) than in A549 cells (less than 10\%) (Plate 2a). Plate 2 (b and c) show MCF-7 and A549 cells, respectively, in which the different response of the two cell types is well evident.

\subsection{DOX accumulation and distribution}

To verify whether the lower sensitivity to DOX evidenced by the MTT assay in A549 cells with respect to MCF-7 cells was due to a reduced intracellular drug concentration, the time course of drug accumulation was determined by flow cytometry and the intracellular drug distribution was analyzed by confocal microscopy. No significant difference in DOX accumulation between the two cell lines was observed after $1 \mathrm{~h}$ of treatment

Table 1

Mean $\mathrm{IC}_{50}$ values

\begin{tabular}{lc}
\hline Cell lines & $\mathrm{IC}_{50}$ \\
\hline MCF-7 & $12.78 \pm 3.11$ \\
A549 & $514.09 \pm 88.64^{*}$ \\
\hline
\end{tabular}

Drug sensitivity, obtained by the MTT assay, was expressed as the drug concentration that inhibits $50 \%$ of cell growth $\left(\mathrm{IC}_{50}\right) .24 \mathrm{~h}$ after seeding, cells were treated with a range of DOX concentrations for 5 days. A549 cells showed to be about 40 times more resistant to DOX than MCF-7 cells $\left({ }^{*} P<0.001\right)$.
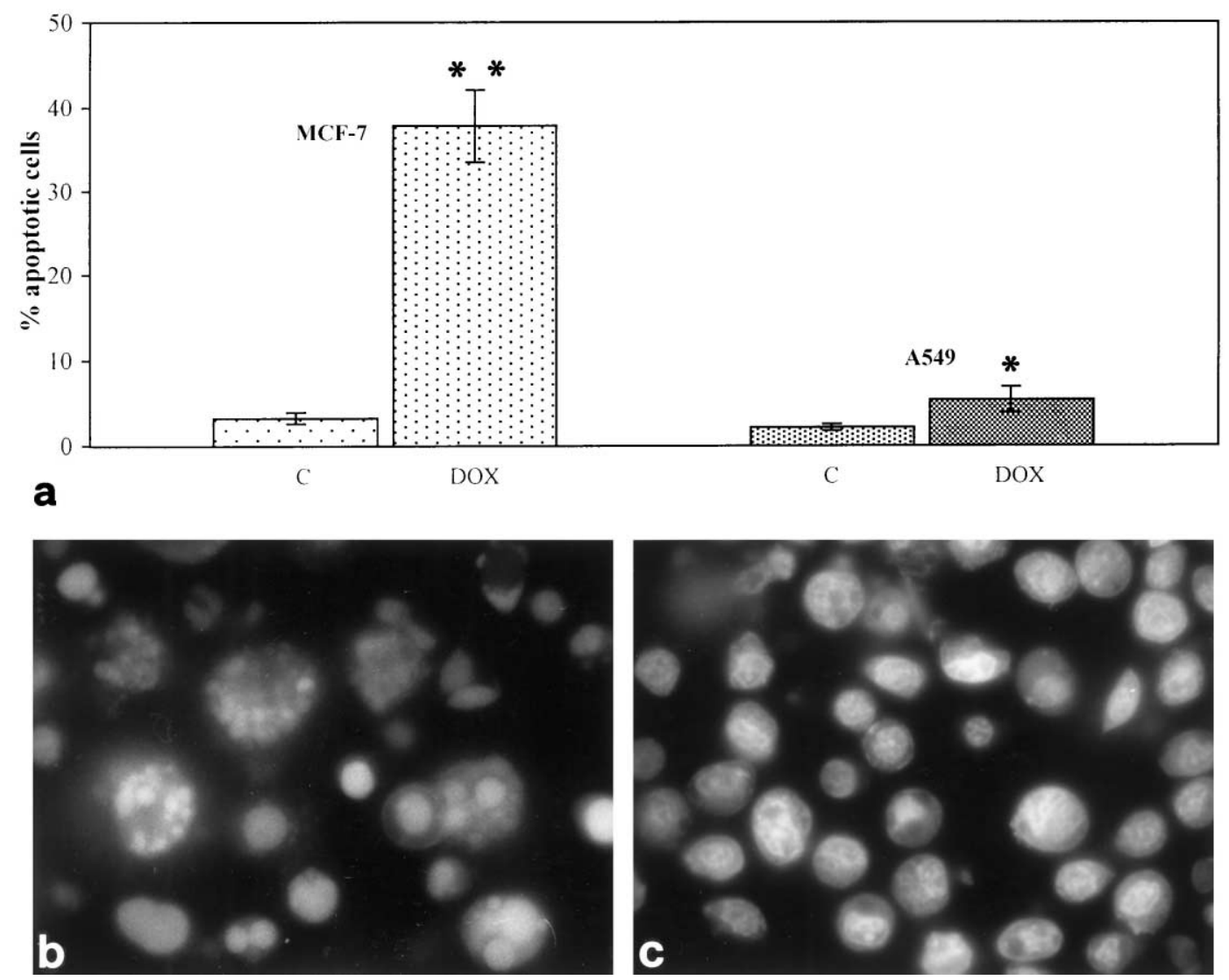

Plate 2. Apoptosis evaluation after Hoechst labelling. Cells were treated with $2 \mu \mathrm{M}$ DOX for $72 \mathrm{~h}$, fixed with paraformaldehyde and stained with 5 $\mu \mathrm{g} / \mathrm{ml}$ Hoechst 33342. (a) The percentage of apoptotic cells ( $y$-axis), calculated by morphological examination of at least 100 cells per sample, was much higher in MCF-7 treated cells ( ${ }^{* *} P<0.01$ when compared to the control) than in A549 treated cells $\left({ }^{*} P<0.05\right.$ when compared to the control). Cells were classified as "normal" when the nuclei were intact and exhibited uncondensed chromatin, as "apoptotic" when perinuclear condensed chromatin or apoptotic bodies were revealed. Fluorescence microscopy analysis showed the different response between (b) MCF-7 and (c) A549 cells $(\mathrm{b}, \times 1500 ; \mathrm{c}, \times 800)$. 

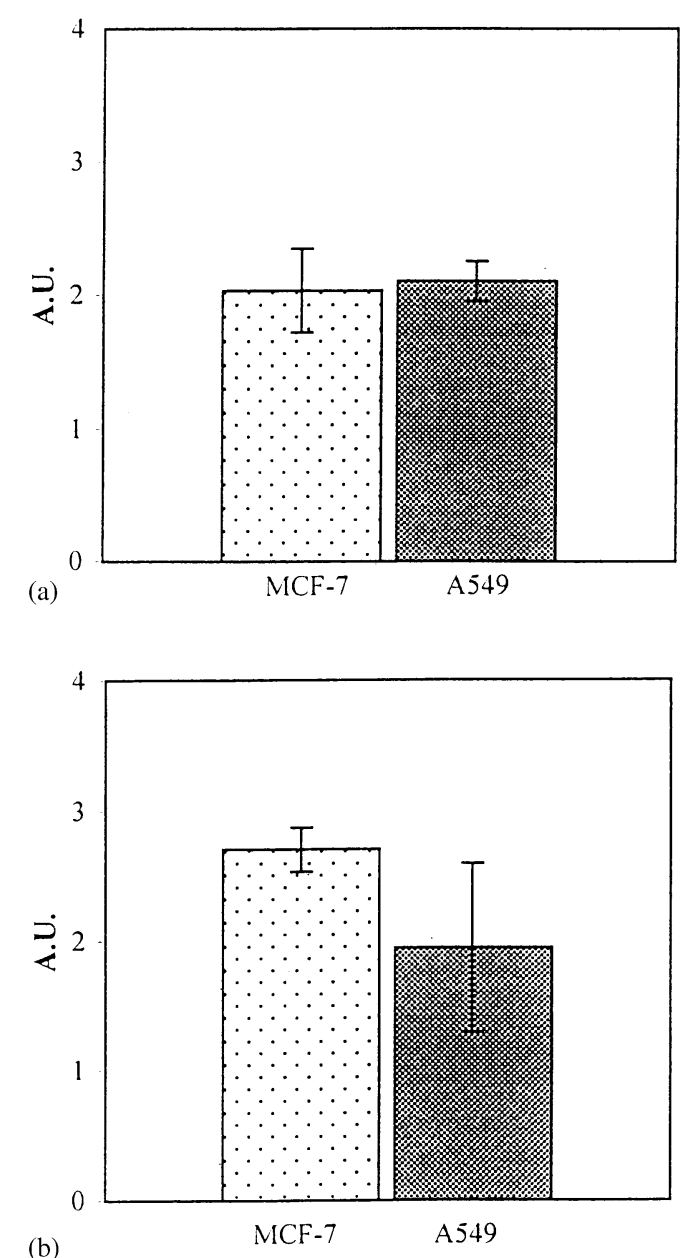

Fig. 1. Flow cytometric analysis of DOX accumulation in MCF-7 and A549 cells. Samples were treated with $2 \mu \mathrm{M}$ DOX for 1 and $4 \mathrm{~h}$, washed with cold HBSS, resuspended in cold PBS and analyzed for drug content. On the y-axis the mean fluorescence channel (MFC) represents the drug fluorescence intensity coming from the cells. After $1 \mathrm{~h}$ of treatment, no significant difference in DOX content could be revealed between the two cell lines, while after $4 \mathrm{~h}$ MCF-7 cells accumulated higher amounts of drug with respect to A549 cells $\left({ }^{*} P<0.05\right)$. with $2 \mu \mathrm{M}$ DOX, while after $4 \mathrm{~h} \mathrm{MCF-7} \mathrm{cells} \mathrm{showed}$ significantly higher intracellular levels of the drug than A549 cells (Fig. 1).

Confocal microscopy revealed a different DOX distribution between the two cell lines during the early phase of the uptake (Plate 3). After 10 min of treatment, MCF-7 cells showed a diffuse fluorescent signal which did not seem to associate with specific intracellular structures (Plate 3a). In contrast, while A549 cells exhibited a lower total fluorescence intensity than MCF-7, this was mainly concentrated in vesicular structures in the perinuclear region (Plate $3 b$ ). The presence of DOX in intracytoplasmic compartments suggested that the anthracycline was localized in cytoplasmic organelles prior to its access to the nucleus. After $30 \mathrm{~min}$ of treatment, higher DOX amounts were already detectable in the nuclei of MCF-7 cells (Plate 3c), as compared to A549 cells (Plate 3d). After $4 \mathrm{~h}$ of treatment, DOX was located inside the nuclei and in the perinuclear region of both cell lines (Plate $3 e$ and $\mathrm{f}$ ), even if a higher fluorescent signal could be detected in MCF-7 cells, confirming flow cytometric determination.

\subsection{P-gp, MRP1 and LRP expression}

Flow cytometric and immunofluorescence microscopy analysis of the expression of the two main drug transporters, P-gp and MRP1, carried out on living cells, revealed that both MCF-7 and A549 cells were completely negative for surface labelling of the two transporters. When flow cytometric analysis was carried out on fixed and permeabilized cells, similar levels of intracytoplasmic P-gp and MRP1 (Fig. 2a and b, respectively) could be detected in the two cell types. In contrast, expression and distribution of the major vault protein LRP were found to be quite different between MCF-7 and A549 cells (Plate 4). Immunoprecipitation

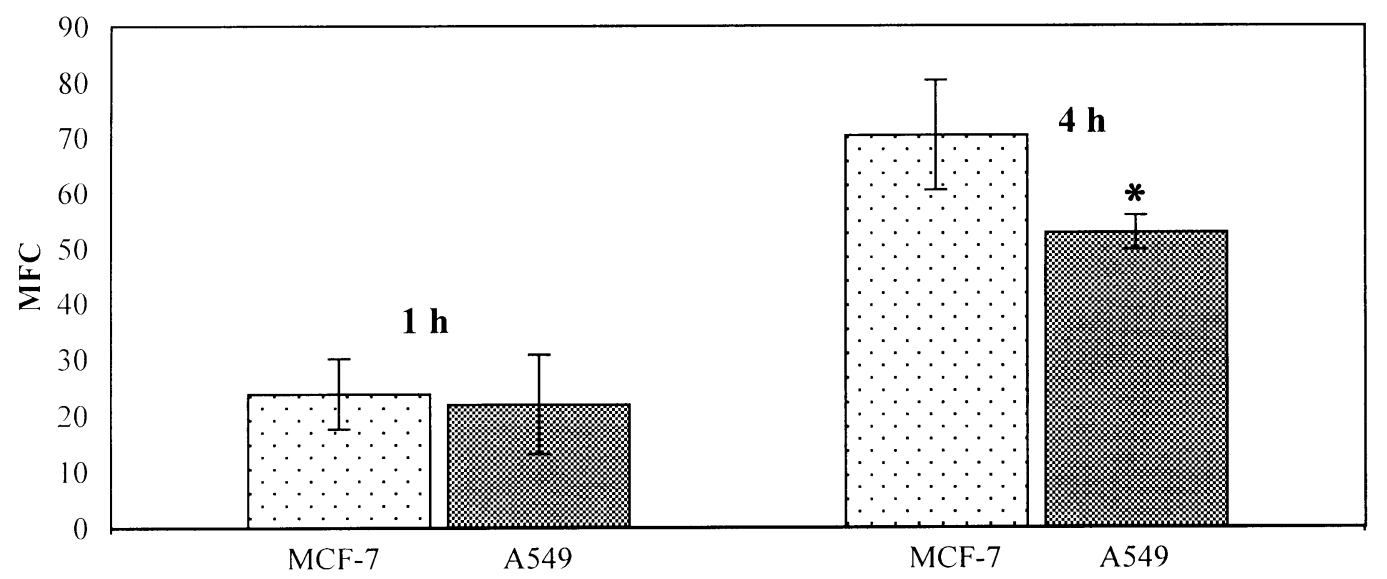

Fig. 2. Flow cytometric analysis of (a) P-gp and (b) MRP expression on MCF-7 and A549 cells. Samples were fixed, permebilized and incubated with MAb MRK16 and a goat anti-mouse IgG fluorescein-conjugate secondary antibody (for P-gp labelling) and with MAb MRPr1 and a goat anti-rat IgG fluorescein-conjugate secondary antibody (for MRP labelling). On the y-axis, protein content was expressed in arbitrary units (A.U.) and calculated as the ratio of the MFC of labelled samples on the MFC of negative controls, obtained by incubating the cells with mouse or rat isotypic globulins. No significant difference in P-gp and MRP expression could be detected between the two cell lines. 
with the anti-LRP MAb LRP-56 revealed the presence of a $110 \mathrm{kDa}$ protein in both cell lines (Plate 4a). However, flow cytometric analysis of MAb LRP-56-labelled samples showed that the fluorescent signal obtained was about twice as intense for A549 cells than for MCF-7 cells (Plate 4b). LSCM observations, carried out under the same immunolabelling conditions, revealed that LRP was virtually undetectable in the more sensitive cell line (MCF-7). In fact, most of MCF-7 cells appeared to be negative for the LRP labelling and only
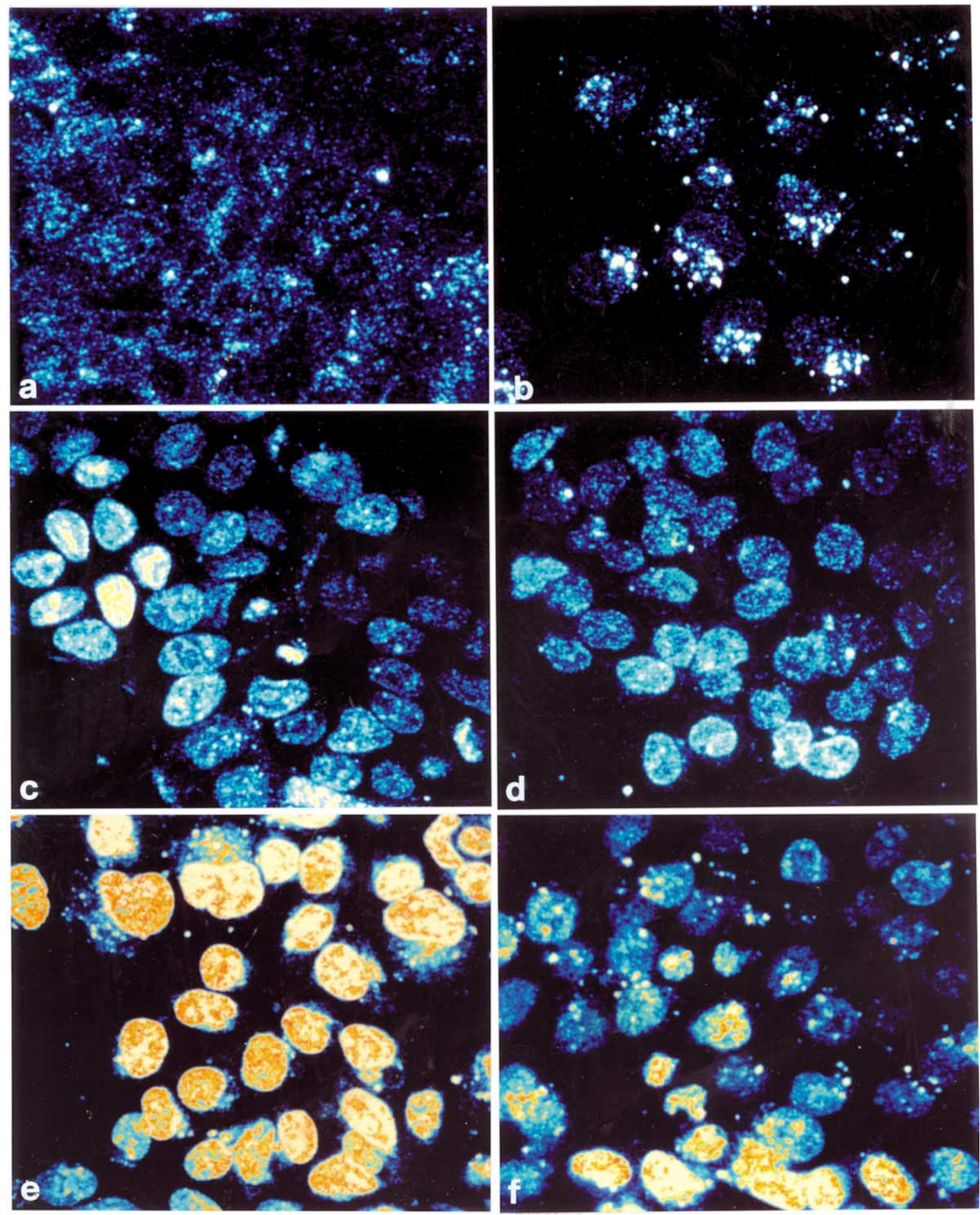

Plate 3. Intracellular DOX distribution in living MCF-7 and A549 cells detected by laser scanning confocal microscopy. (a) MCF-7 cells treated with $2 \mu \mathrm{M}$ DOX for 10 min showed a diffuse fluorescent signal; (b) in contrast, A549 cells showed fluorescent vesicular structures in the perinuclear region. (c) After 30 min of treatment, nuclei of MCF-7 cells contained higher DOX amounts as compared to (d) A549 cells. (e,f) After 4 h of treatment, DOX was located inside the nuclei and in the perinuclear region of both cell lines even if a higher fluorescent signal could be detected in MCF-7 cells, confirming flow cytometric determination. The colour represents the signal intensity with the pseudocolours. Black to white corresponds to minimum to maximum intensity $(\times 800)$. 


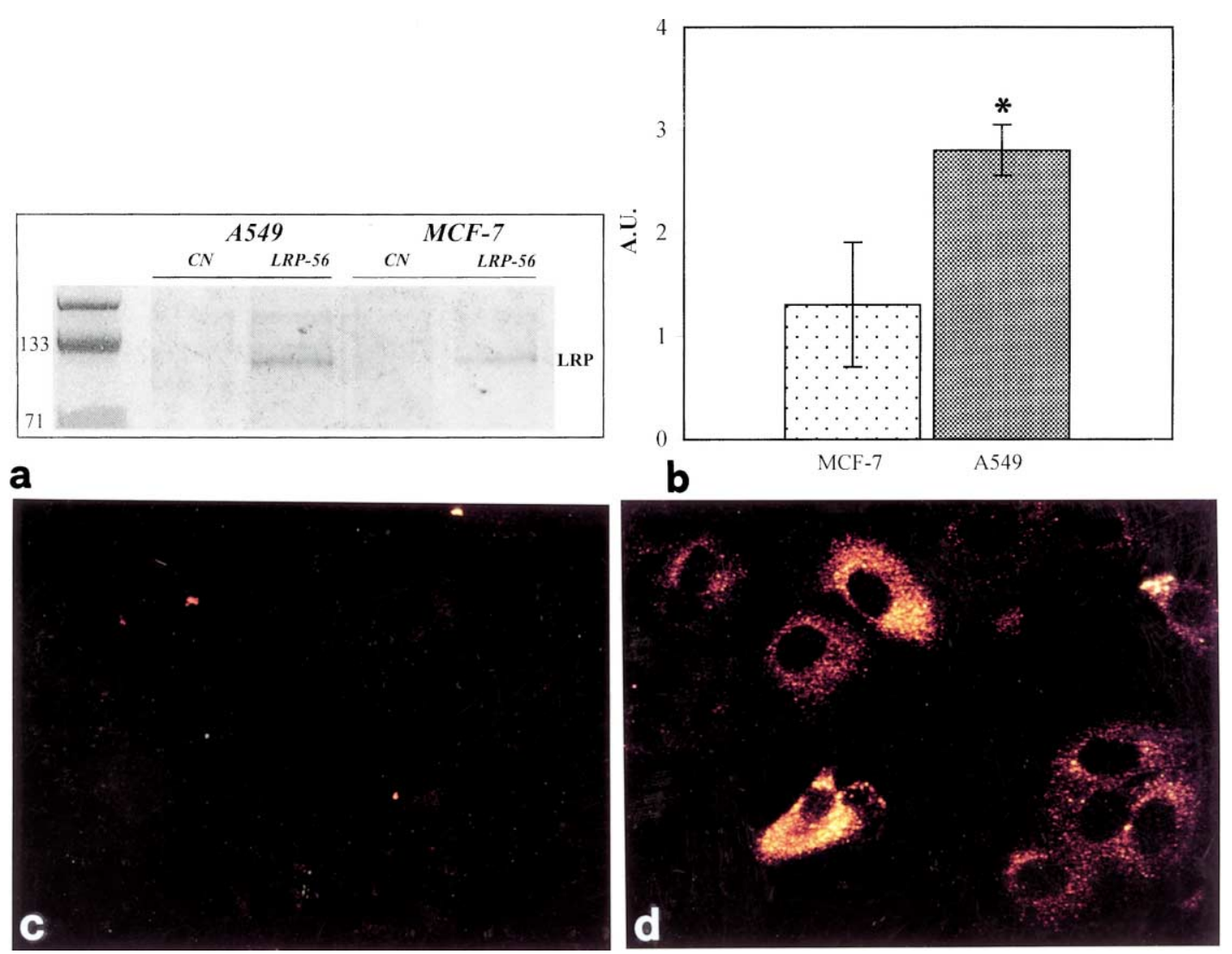

Plate 4. LRP expression and distribution in MCF-7 and A549 cells. (a) Immunoprecipitation analysis with MAb LRP-56 in A549 and in MCF-7 cells. Lysates were immunoprecipitated as described in Materials and methods with LRP-56 or with an irrelevant mouse antibody. No 110 kDa protein was detected in the negative control $(\mathrm{CN})$. Molecular weight is expressed in thousands. (b) Flow cytometric analysis after incubation of samples with MAb LRP-56 and a goat anti-mouse IgG fluorescein-conjugate secondary antibody. On the y-axis, protein content was expressed in arbitrary units (A.U.) and calculated as the ratio of the MFC of labelled samples on the MFC of negative controls, obtained by incubating the cells with mouse isotypic globulins. A549 showed to express higher levels of LRP than MFC-7 cells $(* P<0.05)$. LSCM of (c) MCF-7 cells and (d) A549 cells after labelling with MAb LRP-56 revealed that breast cancer cells were quite negative while lung carcinoma cells showed a strong fluorescent signals arising from the cytoplasm $(\times 500)$.

a few cells displayed a weak fluorescence (Plate 4c). Conversely, most of A549 cells were LRP-positive, with a punctate pattern of immunofluorescent labelling around the nuclei and in the cytoplasm (Plate 4d). Similar results were obtained following incubation with MAb LRP-42 (data not shown).

\section{Discussion}

Intrinsic drug resistance to anticancer agents is one of the most serious obstacles to successful cancer chemotherapy (Dong et al., 1992). It is well known that cancer cells with different histotypes show significant differences in the response to the cytotoxic effect of various antineoplastic agents. Such differential drug sensitivity depends on a number of cellular components and metabolic pathways, most of which are not yet completely elucidated. To gain a better insight into the mechanisms underlying the intrinsically resistant phenotype, two human cell lines, MCF-7 breast adeno- carcinoma and A549 non small cell lung cancer (NSCLC), which show different sensitivity to DOX, have been analysed.

Lung carcinoma cells actually exhibited a spontaneous resistance to drug treatment, which was about 40 times as high as breast cancer cells. Flow cytometric analysis revealed that A549 cells accumulated lower intracellular drug amounts following $4 \mathrm{~h}$ incubation with DOX, while the observations performed by LSCM on living cells evidenced marked differences in intracellular DOX distribution between the two cell lines. These findings are in agreement with the results of a previous study (Dolfini et al., 1997), which showed a decreased drug accumulation in a LoVo human colon adenocarcinoma cell clone characterized by low-level spontaneous resistance to DOX (LoVo 7) when compared to the parental cell population (LoVo WT). Moreover, several Authors have reported a decrease in the nuclear/ cytoplasmic ratios of DOX amount in a number of resistant cell lines (Willingham et al., 1986; Meschini et al., 1994; Arancia et al., 1998). 
A close relationship between changes in intracellular drug accumulation and distribution and the expression and localization of different drug transporters commonly implicated in drug resistance has been extensively demonstrated (Schuurhuis et al., 1991; Molinari et al., 1994, 1998; Dolfini et al., 1997). In our cell models, analysis of P-gp and MRP1 expression by flow cytometry and confocal microscopy failed to detect any significant difference in the content of these proteins between the two cell lines, suggesting that neither P-gp nor MRP1 plays a major role in determining the observed differences in drug accumulation and intracellular distribution. In contrast, both flow cytometry and immunoprecipitation demonstrated higher levels of LRP expression in unselected A549 cells, which showed lower sensitivity to DOX treatment. Several experimental findings indicate that LRP could participate in cytoprotective processes preventing access of cytotoxic drugs and xenobiotics to cytoplasmic and/or nuclear targets (Izquierdo et al., 1996; Laurencot et al., 1997; Kickhoefer et al., 1998; Dalton and Scheper, 1999). Recently, Berger et al. (2000) demonstrated the presence of LRP mRNA and protein in a number of untreated NSCLC cell lines, suggesting that this drug transporter might play an important role in the defensive response of NSCLC cells against chemotherapeutic drugs. Moreover, direct involvement of LRP in the occurrence of a resistant phenotype to DOX was demonstrated in a human colon carcinoma cell line, SW-620, which did not express P-gp and MRP, but nevertheless developed resistance to DOX by upregulating LRP expression following treatment with sodium butyrate (Kitazono et al., 2001). In this cell line, LRP was shown to mediate DOX export from the nucleus to the cytoplasm, and its role in resistance to DOX was confirmed by the observation that the new inhibitor PAK-104 P, which interferes with drug transport by LRP as well as by P-gp and MRP1 (Shudo et al., 1990; Sumizawa et al., 1997), was able to reverse, at least in part, the MDR phenotype in this P$\mathrm{gp} / \mathrm{MRP1}$-negative cell line.

Our confocal microscopic observations showed that LRP colocalized with DOX in same vesicular structures in the cytoplasm and in the perinuclear region, suggesting that the role of this protein in MDR consist in sequestering cytotoxic drugs away from the nucleus. Previous studies by our group showed that in druginduced MDR cells P-gp was also localized in the Golgi apparatus and in cytoplasmic vesicles (Molinari et al., 1994) and had therefore been proposed to contribute to cellular defense mechanisms against xenobiotics by sequestering DOX within the cytoplasm.

The low level of LRP expression detected in MCF-7 cells, in complete agreement with the results of a number of previous studies (Izquierdo et al., 1996; Kickhoefer et al., 1998), might account for the characteristic sensitivity displayed by breast tumor cells to DOX treatment in vitro and possibly for the higher rate of response of this tumor type to clinical treatments. Further investigations will be required to identify the mechanisms regulating LRP overexpression in resistant cells; however, the results of the present study indicate that LRP, together with an increasing number of markers of intrinsic drug resistance, might provide valuable clues as to the pattern of drug sensitivity of individual tumors, thus helping to design more effective treatment protocols for the clinical management of human malignancies.

\section{Acknowledgements}

We wish to thank Mr. L. Camilli for valuable technical assistance.

\section{References}

Alley, M.C., Scudiero, D.A., Monks, A., Hursey, M.L., Czerwinski, M.J., Fine, D.L., Abbot, B.J., Mayo, J.G., Shoemaker, R.H., Boyd, M.R., 1988. Feasibility of drug screening with panels of human tumor cell lines using a microculture tetrazolium assay. Cancer Research 48, 589-601.

Arancia, G., Calcabrini, A., Meschini, S., Molinari, A., 1998. Intracellular distribution of anthracyclines in drug resistant cells. Cytotechnology 27, 95-111.

Berger, W., Elbling, L., Hauptmann, E., Micksche, M., 1997. Expression of multidrug resistance-associated protein (MRP) and chemoresistance of human non-small-cell lung cancer cells. International Journal of Cancer 73, 84-93.

Berger, W., Elbling, L., Micksche, M., 2000. Expression of the major vault protein L. R. P. in human non-small-cell lung cancer cells: activation by short-term exposure to antineoplastic drugs. International Journal of Cancer 88, 293-300.

Childs, S., Ling, V., 1994. The M. D. R. superfamily of genes and its biological implications. In: De Vita, V.T., Helleman, S., Rosenberg, S.A. (Eds.), Important Advances in Oncology. J.B. Lippincott Company, Philadelphia, pp. 21-36.

Clarke, R., Dickson, R.B., Brünner, N., 1990. The process of malignant progression in human breast cancer. Annals of Oncology 1, 401-407.

Cole, S.P.C., Bhardway, G., Gerlach, J.H., Mackie, J.E., Grant, C.E., Almquist, K.C., Stewart, A.J., Kurz, E.U., Duncan, A.M.V., Deeley, R.G., 1992. Overexpression of a transporter gene in a multidrug resistant human lung cancer cell line. Science (Wash 258, 16501654.

Dalton, W.S., Scheper, R.J., 1999. Lung resistance-related protein: determining its role in multidrug resistance. Journal of the National Cancer Institute 91, 1604-1605.

Dietel, M., Arps, H., Lage, H., Niendorf, A., 1990. Membrane vesicle formation due to acquired mitoxantrone resistance in human gastric carcinoma cell line PG85-257. Cancer Research 50, 6100-6106.

Dolfini, E., Dasdia, T., Arancia, G., Molinari, A., Calcabrini, A., Scheper, R.J., Flens, M.J., Gariboldi, M.B., Monti, E., 1997. Characterization of a clonal human colon adenocarcinoma line intrinsically resistant to doxorubicin. British Journal of Cancer 76, 67-76.

Dong, Z., Ward, N.E., Fan, D., Gupta, K., O'Brian, C.A., 1992. In vitro model for intrinsic drug resistance: effects of protein kinase $\mathrm{C}$ activators on the chemosensitivity of cultured human colon cancer cells. Molecular Pharmacology 39, 563-569. 
Doyle, L.A., 1993. Mechanisms of drug resistance in human lung cancer cells. Seminars in Oncology 20, 326-337.

Flens, M.J., Izquierdo, M.A., Scheffer, G.L., Schroeijers, A.B., Fritz, J.M., Meijer, C.J.L.M., Scheper, R.J., Zaman, G.J.R., 1994. Immunochemical detection of M. R. P. in human multidrug-resistant tumor cells by monoclonal antibodies. Cancer Research 54, 4557-4563.

Gottesman, M.M., Pastan, I., 1993. Biochemistry of multidrug resistance mediated by the multidrug transporter. Annual Reviews of Biochemistry 62, 385-427.

Izquierdo, M.A., Scheffer, G.L., Flens, M.J., Giaccone, G., Broxterman, H.J., Meijer, C.J., van der Valk, P., Scheper, R.J., 1996. Broad distribution of the multidrug resistance-related vault lung resistance protein in normal human tissues and tumours. American Journal of Pathology 148, 877-887.

Kedersha, N.L., Miquel, M.C., Bittner, D., Rome, L.H., 1990. Vaults. II. Ribonucleoprotein structures are highly conserved among higher and lower eukaryotes. Journal of Cell Biology 110, 895-901.

Kickhoefer, W.A., Rajavel, K.S., Scheffer, G.L., Dalton, W.S., Scheper, R.J., Rome, L.H., 1998. Vaults are up-regulated in multidrugresistant cancer cell lines. The Journal of Biological Chemistry 273, 8971-8974.

Kitazono, M., Okumura, H., Ikeda, R., Sumizawa, T., Furukawa, T., Nagayama, S., Seto, K., Aikou, T., Akiyama, S., 2001. Reversal of L. P. R.- associated drug resistance in colon carcinoma SW-620 cells. International Journal of Cancer 91, 126-131.

Laurencot, C.M., Scheffer, G.L., Scheper, R.J., Shoemaker, R.H., 1997. Increased L. R. P. mRNA expression is associated with the M. D. R. phenotype in intrinsically resistant human cancer cell lines. International Journal of Cancer 72, 1021-1026.

Leonessa, F., Boulay, V., Wright, A., Thompson, E.W., Brünner, N., Clarke, R., 1992. The biology of breast tumour progression. Acta Oncologica 31, 115-123.

Meschini, S., Calcabrini, A., Monti, E., Del, Bufalo., Stringaro, D., Dolfini, A., Arancia, E.G., 2000. Intracellular P-glycoprotein expression is associated with the intrinsic multidrug resistance phenotype in human colon adenocarcinoma cells. International Journal of Cancer 87, 615-628.

Meschini, S., Molinari, A., Calcabrini, A., Citro, G., Arancia, G., 1994. Intracellular localization of the antitumor drug adriamycin in living cultured cells: a confocal microscopy study. Journal of Microscopy 176, 204-210.
Molinari, A., Calcabrini, A., Meschini, S., Stringaro, A., Del, Bufalo., Cianfriglia, D., Arancia, M.G., 1998. Detection of P-glycoprotein in the Golgi apparatus of drug-untreated human melanoma cells. International Journal of Cancer 75, 885-893.

Molinari, A., Cianfriglia, M., Meschini, S., Calcabrini, A., Arancia, G., 1994. P-glycoprotein expression in the Golgi apparatus of multidrug-resistant cells. International Journal of Cancer 59, 789795 .

Scheffer, G.L., Wijngaard, P.L.J., Flens, M.J., Izquierdo, M.A., Slovak, M.L., Pinedo, H.M., Meijer, C.J.L.M., Clevers, H.C., Scheper, R.J., 1995. The drug resistance-related protein L. R. P. is the human major vault protein. Nature Medicine 1, 578-582.

Scheper, R.J., Broxterman, H.J., Scheffer, G.L., Kaaiijk, P., Dalton, W.S., van, Heijningen, T.H., van, Kalken, C.K., Slovak, M.L., de, Vries, E.G., van der, Valk, P., Meijer, C.J.L.M., Pinedo, H.M., 1993. Overexpression of a M(r) 110,000 vesicular protein in non Pglycoprotein-mediated multidrug resistance. Cancer Research 53, $1475-1479$.

Schuurhuis, G.J., Broxterman, H.J., de, Lange, J.H.M., Pinedo, H.M., van, Heijningen, T.H., Kuiper, C.M., Scheffer, G.L., Scheper, R.J, van, Kalken, C.K., Baak, M., Lunkelma, J., 1991. Early multidrug resistance, defined by changes in intracellular doxorubicin distribution, independent of P-glycoprotein. British Journal of Cancer 64, $857-861$.

Shapiro, A.B., Ling, V., 1995. Using purified P-glycoprotein to understand multidrug resistance. Journal of Bioenergetics and Biomembranes 27, 7-13.

Shudo, N., Mizoguchi, T., Kiyosue, T., Arita, M., Yoshimura, A., Seto, K., Sakoda, R., Akiyama, S., 1990. Two pyridine analogues with more effective ability to reverse multidrug resistance and with lower calcium channel blocking activity than their dihydropyridine counterparts. Cancer Research 50, 3055-3061.

Sumizawa, T., Chen, Z.S., Chuman, Y., Seto, K., Furukawa, T., Haraguchi, M., Tani, A., Shudo, N., Akiyama, S.I., 1997. Reversal of multidrug resistance-associated protein-mediated drug resistance by the pyridine analog P. A. K.-104P. Molecular Pharmacology 51, 399-405.

Willingham, M.C., Cornwell, M.M., Cardarelli, C.O., Gottesman, M.M., Pastan, I., 1986. Single cell analysis of daunomycin uptake and efflux in multidrug-resistant and -sensitive KB cells: effect of verapamil and other drugs. Cancer Research 46, 5941-5946. 